\title{
CESAR GUIMARÃES: UM PROFESSOR
}

César Guimarães: a professor

Matheus de Sá Moravia ${ }^{1}$

Rafael Rezende ${ }^{2}$

1 Doutorando em Ciência Política pelo Instituto de Estudos Sociais e Políticos da Universidade do Estado do Rio de Janeiro (IESP-UERJ). Bolsista FAPERK Nota 10. E-mail: brozrezende@gmail.com

2Doutorando em Sociologia pelo Instituto de Estudos Sociais e Políticos da Universidade do Estado do Rio de Janeiro (IESP-UERJ). O presente trabalho foi realizado com apoio da Coordenação de Aperfeiçoamento de Pessoal de Nível Superior - Brasil (CAPES) - Código de Financiamento 001. E-mail: matheus.moravia@gmail.com 


\begin{abstract}
RESUMO
Cesar Coelho Guimarães é um dos percussores da Ciência Política no Brasil e um dos maiores pensadores vivos da política. Erudito, Cesar é conhecido por sua gigantesca e fundamental obra, embora cada vez menos valorizada: um vasto e profundo conhecimento teórico não especializado em apenas uma grande área e um apreço verdadeiro pela docência. Transita pelos mais diversos campos do conhecimento com naturalidade. Ensina seus alunos com preocupação intensa no aprendizado de todos, com sabedoria e rigor, sensibilidade e clareza. Em tempos de tanto ódio e incerteza, sua disciplina pessoal na dedicação à docência se confunde cotidianamente com seu profundo respeito aos seres humanos e suas vidas, sinais claros de um homem que exala demofilia em suas ações. Próximo de seu aniversário de 80 anos, quase todos dedicados à formação teórica de diversos cientistas brasileiros, o professor Cesar Guimarães recebe esse delicado texto como uma merecida homenagem de seus alunos.
\end{abstract}

PALAVRAS-CHAVE: Cesar Guimarães; Pioneiros; Professor; Homenagem.

\begin{abstract}
Cesar Coelho Guimarães is one of the percussors of political science in Brazil and one of the greatest living thinkers of politics. Erudite, Cesar is known for his gigantic and fundamental work, though less and less valued: a vast and deep theoretical knowledge unspecialized in just a large area and a true appreciation for teaching. He moves around through the most diverse fields of knowledge with plainness. He teaches his students with an intense concern for everyone's learning, with wisdom and rigor, sensitivity and clarity. In times of such hate and uncertainty, his personal discipline in his dedication to teach is often confused with his deep respect for human beings and their lives, clear signs of a man who exhales demophilia in his actions. Cesar has always been present to remember is about the lives of the people we are talking about. Near his 80th birthday, almost all dedicated to the theoretical formation of several Brazilian scientists, Professor Cesar Guimarães receives this delicate text as a welldeserved tribute from his students.
\end{abstract}

KEYWORDS: Cesar Guimarães; Pioneers; Professor; Tribute. 
A história do Instituto de Estudos Sociais e Políticos (IESP-UERJ), outrora Instituto Universitário de Pesquisas do Rio de Janeiro (IUPERJ), um dos mais importantes institutos de pesquisa e ensino do Brasil, se confunde com a de um notório professor: Cesar Guimarães.

Cientista político e professor carioca, Cesar Coelho Guimarães nasceu e foi criado em Botafogo, bairro que abrigou o Instituto Superior de Estudos Brasileiros (ISEB) e posteriormente o IUPERJ e o IESP-UERJ. Estudou no tradicional Colégio Santo Inácio, colégio particular pertencente à Companhia de Jesus localizado na mesma vizinhança. Na vida adulta, foi estudar na Faculdade Nacional de Direito (FND), onde aproximou-se do movimento estudantil naqueles agitados anos que precederam o golpe militar. Não tardou para que percebesse que os lírios não nascem das leis e, consequentemente, seu desinteresse pelo direito tornou-se inversamente proporcional ao seu interesse pela política e pela filosofia. Guimarães, então, partiu para a Califórnia com o intuito de fazer mestrado numa carreira que, no Brasil, ainda engatinhava: a Ciência Política. Ao retornar, vinculou-se ao IUPERJ (agora IESP-UERJ), onde leciona e orienta teses há mais de cinquenta anos, tendo formado gerações de profissionais.

Política externa estadunidense, democracia e filosofia política são os temas que despertaram o interesse acadêmico de Guimarães, no entanto, quem tem a oportunidade de conversar com o velho professor ou assistir uma de suas aulas, fica com a impressão de que seu conhecimento é ilimitado. Guimarães é um erudito. De pensamento sofisticado, humor ácido e compreensão perspicaz, suas aulas nem sempre são fáceis de acompanhar. Não vá esperando um curso introdutório, uma vez que o olhar lançado por Guimarães sobre os textos ignora as obviedades e busca lançar luz naquilo que nem sempre se vê. Aliás, é mister citar, a sala de aula é o seu habitat natural. Como boa parte dos povos subsaarianos, Guimarães é um adepto da tradição oral. Através da fala solta e articulada, ele transmite conhecimento como poucos e provoca os estudantes a pensarem de maneira autônoma sem 
descuidarem do necessário embasamento teórico. Também sábio das competências mais amplas, como a prudência, a moral e experiência de vida, suas referências se perdem numa imensidão de conhecimento, que transmite com paixão evidente. Se necessário for para transmitir aquilo que julga importante para o aprendizado de seus alunos, transita pela literatura, cinema, ou até exemplos de sua vida íntima com facilidade e humildade ímpar. Em resumo: se o mundo é uma grande escola, Cesar é um grande professor.

Quem vivencia o dia-a-dia das universidades e institutos de pesquisa convive com muitos acadêmicos, mas aprende logo: intelectuais são poucos. É possível, inclusive, contá-los nos dedos das mãos. Guimarães, sem dúvida alguma, é um intelectual, isto é, alguém que disponibiliza seu conhecimento para o público, que faz do saber uma ferramenta potente de crítica e transformação. Sempre inquieto, questionador - e, por vezes, rebelde - o professor incita a pesquisa cientifica não como um fim em si, mas como um projeto de questionamento profundo sobre a relação entre o indivíduo e a sociedade. Dessa forma, Guimarães não dissimula sua radicalmente democrática crítica ao modo capitalista de produção e ao autoritarismo: seja na política brasileira, seja nas dominações cotidianas presentes em suas relações sociais.

No trato com os estudantes, especialmente aqueles cuja pesquisa está sob sua orientação, seu rigor é proporcional a sua generosidade, isto é, enorme. Ser humano sensível e mente indócil, Guimarães atua como uma espécie de imperfeito bibliotecário em uma biblioteca infinita. Como se desconhecesse os muros construídos entre as disciplinas, ele adentra a Sociologia, a Política, a Filosofia, o Direito, a História e a Economia com naturalidade, como se as divisões entre umas e outras fossem apenas prateleiras que deselegantemente separam pensamentos. Inimigo de toda especialização extremada - e da ignorância decorrente -, aos estudantes, demonstra que o saber é fundado na expansão dos interesses e não na retração dos campos de estudo. Nesse sentido, Guimarães nos ensina a encarar a teoria política em toda a sua 
amplitude, jamais aceitando que ela sirva de alimento processado para frívolos debates academicistas que abundam, hoje em dia, nas universidades.

Talvez o rótulo não agrade o experiente professor, mas seria desonesto não mencionar que Guimarães é um marxista, mesmo que com pouco ou nenhuma dialética. Crítico das experiências socialistas do século XX, uma vez que é um democrata radical - e, neste ponto, democracia deve ser entendida como prática e não apenas como regime -, o marxismo para ele é muito mais um conjunto de ideias das quais serve-se para interpretar o mundo do que um projeto político. Não se engane, de Marx, ele tem bem claro o sentido de que é a luta de pessoas contra injustiças imposta pela sociedade que escreve a história da humanidade. E isto quer dizer, obviamente, que ele não se furta de assumir posições, como outros tantos acadêmicos fazem achando que isso demonstra sensatez. Como intelectual que é, Guimarães foi um detrator da ditadura militar, do retorno do liberalismo econômico e, recentemente, do golpe efetuado sobre o Partido dos Trabalhadores. Crítico voraz da economia política, ele filiou-se, assim por dizer, a economia política crítica, o que, na ciência política, reflete-se no seu profundo antielitismo na maneira de pensar o mundo.

Boa parte dos seus trabalhos publicados têm como objeto a política externa estadunidense, a qual Guimarães tece duras crítica e considera como imperial. Também se debruçou sobre outros temas como a democracia e a política brasileira, tendo sempre a história como pulsante elemento transversal aos seus escritos e falas. E se é verdade que "articular o passado historicamente não significa conhecê-lo tal como ele propriamente foi. Significa apoderar-se de uma lembrança tal como ela lampeja num instante de perigo" (BENJAMIN, 2005: p. 75), Guimarães, tal como um personagem de um conto de Borges, sabe a hora sem precisar consultar o relógio. E é por isso que a história não lhe serve de bengala nostálgica, mas como um porrete para o presente.

São pelo menos três as gerações de cientista políticos, sociólogos e historiadores que tiveram a oportunidade de acompanhar suas aulas, seja no 
IUPERJ, no IESP-UERJ ou na Pontifícia Universidade Católica (PUC-Rio). Leituras densas e textos dissecados na sua fala mansa e áspera ironia. Seja ensinando Aristóteles e Platão, Hobbes, Rousseau e Espinoza, De Maistre e Burke, Robespierre e Sieyès, Mill e Spencer, Lênin e Schumpeter, Guimarães trata de recuperar a teoria e afirmar o ensino como liberação, como uma aventura de um viajante por trilhas nas quais nenhuma caminhada será como a anterior. Aprender e ensinar como, de fato, uma relação que, não livre de percalços, ao fim impulsiona o estudante a um nível mais alto de conhecimento onde o saber não se torna mera reprodução.

Certamente, o professor Cesar Guimarães ficará contente se informado ao leitor de sua profunda irritação com teorias baseadas no princípio da tolerância. Tolerar nunca é o suficiente para um professor como ele, que não cobrará nada além do profundo respeito pelos seres humanos. Respeitar não é amar - e seu extremo apreço pela materialidade da vida e aversão a argumentos transcendentais, quando vazios, não suportaria tamanha demanda cristã de amarmos uns aos outros (ao menos não analiticamente). Entretanto, respeitar é muito mais que tolerar. É amar a existência, claro, dirão os leitores mais espinozianos. Mas também é saber atribuir responsabilidades, ser rigoroso, exigir de cada um que lance incessantes luzes sobre onde há escuridão. $\mathrm{O}$ professor Cesar sempre cobra respeito em todas as esferas da vida para que se possa aprender, valorizar o conhecimento humano. É necessário respeitar o interlocutor para ser rigoroso na crítica. Respeitar a história para ser rigoroso na análise. Respeitar-se, sempre, para conseguir ir adiante, pois sempre haverá obstáculos para quem quer iluminar o mundo. Respeitar o mundo para aprender a não ser pego de surpresa e poder se preparar. "Viver" confidenciou Cesar um dia - "é ir em frente, na contramão da história burra. E para isso sempre haverá um preço a ser pago".

Em suma, o pioneirismo de Guimarães certamente não está na inovação da sua obra e nem na originalidade do conteúdo de suas aulas, mas em sua vida profissional dedicada ao ensino na concepção mais abrangente do 
termo. Como professor, colaborou com a produção de um campo de estudos relativamente novo, formando de maneira exemplar o que há de mais indispensável para a ciência política: os/as cientistas políticos. Livros e honrarias de nada servem sem as pessoas, o fundamento de toda e qualquer ciência social. Guimarães, sem dúvida, trabalha para as pessoas.

Em um momento de ódio à democracia, é necessário lembrar que o pioneirismo não passa apenas pelo simples desejo de obter sucesso ao construir algo inédito, como se o mundo fosse uma grande mesa de jantar, servida para satisfazer os que têm desejos. O pioneiro é aquele que tem sabedoria para saber que é preciso esforço rotineiro para construir algo que um dia venha a parecer óbvio, natural, para gerações futuras. Para lembrar rotineiramente que o mundo não acontece pelo acaso e que é preciso trabalhar para não enlouquecer em meio às suas injustiças. Que, em meio ao caos, arruma forças para se levantar diariamente para caminhar e lutar pela construção do respeito entre seres humanos. Para trabalhar pelo comum, sendo crítico a cada uma das desigualdades estamentais que tentam se impor sobre ele. Para ter coragem de ser humilde e se entender como parte de algo maior, num exercício extremo de demofilia. Em meio aos que tentam tampar a luz do sol para dominar, o velho professor de política Cesar Guimarães segue levantando a voz para ensinar a todos os seus alunos algo que nunca dever ser esquecido sobre o mundo: "é política, porra!".

\section{REFERÊNCIAS}

BENJAMIN, Walter. (2005), "Sobre o conceito de história", in. M. LOWY (ed.), Walter Benjamin: aviso de incêndio: uma leitura das teses "Sobre o conceito de história”. São Paulo, Boitempo, pp. 33-146. 